\title{
Experimental investigation biodiesel-n-butanol fuels blends on performance and emissions in the diesel engine
}

ARTICLE INFO

Received: 18 July 2021

Revised: 3 September 2021

Accepted: 8 September 2021

Available online: 23 September 2021
The paper presents the experimental test results reflecting the comparative changes in the performance efficiency and emissions of the exhaust of a naturally aspirated, four-stroke, single-cylinder, air-cooled diesel engine due to its transition from neat rapeseed oil biodiesel to fuel blends prepared by mixing in various proportion (by volume) rapeseed methyl ester $(B)$ and butanol $(B u)$. The lubricity properties of biodiesel- $n$ butanol fuel blends were studied using HFRR method. In contrast to previous works, the undertaken investigation is performed with a totally renewable, binary liquid biofuel blends. The purpose of the research is to reduce simultaneously the production of $\mathrm{NO}_{x}$ emissions and the exhaust smoke with respect to neat biodiesel due to potentially improved homogeneity of combustible mixture and particulate matter emissions benefits suggested by the higher oxygen content $(21.62 \mathrm{wt} \%)$ and the relatively lower carbon-to-hydrogen ratio (4.8) of the normal nbutanol. The tests revealed that the brake specific fuel consumption for the binary biodiesel-n-butanol fuel blends is always higher than that neat biodiesel produces under the same loading conditions. Maximum nitrogen oxide $\left(N O_{x}\right)$ emissions were obtained with the engine running on neat biodiesel (2290 ppm). At full (100\%) load conditions, the lowest $N O_{x}$ emission was obtained with the engine running on a biofuel BBu2O blend. The lowest level of carbon monoxide emissions $(\mathrm{CO})$ was observed, when engine running with the most butanol-oxygenated biofuel blend BBu20.The highest smoke opacity of the exhaust was obtained when the engine was fuelled with neat biodiesel and at full load.

Key words: diesel engine, biodiesel, n-butanol, lubricity, brake specific fuel consumption, engine efficiency, emissions, smoke opacity

This is an open access article under the CC BY license (http://creativecommons.org/licenses/BY/4.0/)

\section{Introduction}

In the recent decades, the scientists continue to work on the rational global energy using as well as urgent ecological and environmental problems. The requirements stated by the EU parliamentarians to intensify the development of renewable energy sources, strict environmental requests associated with the reduction of greenhouse gas emissions and wastes in the municipal economy, agricultural and forestry sectors encourage the researchers to investigate alternative and renewable energy strategies including a wider use of biofuels. Up to now, the researchers have not offered new technological solutions that would completely replace internal combustion engines by other mechanical energy sources. For this reason, oil and the natural gas reserves rapidly decrease over the recent decades. Moreover, smoke and exhaust emissions produced by internal combustion engines cause serious damage to the ecological system. The Directive 2009/28/EC of the European Parliament and the Council on the promotion of the use of energy from renewable sources approved a target of a $20 \%$ of European energy consumption using renewable fuels in a costeffective way [1]. This Directive fixes the minimum consumption of renewable fuel used in transport-sector and creates a challenge for both the scientists and the industry. Agriculture and transport sectors are among the largest fossil fuel consumers and therefore can be regarded as the biggest contributors to the environmental pollution. The mineral diesel fuel traditionally remains the most popular among the others motor fuels. Consumption of the diesel fuel has been growing steadily over the last two decades.

The physical properties of the fuel such as density, viscosity and bulk modulus of compressibility affect the deliv- ery rate and the injection characteristics and thus the quality of the air and the fuel mixture, which in turn affects the combustion process, brake thermal efficiency and the ecological parameters of the diesel engine. Specific properties of alternative and renewable biofuels such as density, viscosity, calorific value, cetane number, freezing point, etc. differ from those of the normal diesel fuel. Keeping in a track with the newest trends to use lighter and more environment friendly biofuels for a diesel engine powering, Giakoumis et al. [2], Rakopoulos et al. [3], Labeckas et al. [4] tested n-butanol in diesel fuel blends. The research revealed [4], due to the longer auto-ignition delay period of a pilot portion of diesel-n-butanol fuel blends both the fuelenergy conversion efficiency representing burn angle MBF50, at which burns a half of the injected fuel portion, and the end of combustion occur earlier in an engine cycle after TDC. In result, the brake thermal efficiency increases to maximum value of 0.383 when running with diesel fuel blend involving n-butanol DB3 (3.0 wt\% oxygen) at speed of $1800 \mathrm{rpm}$. While the $\mathrm{NO}_{\mathrm{x}}, \mathrm{CO}$ and THC emissions decrease by $5.1 \%, 29.5 \%$ and 3.7 times, respectively, when running with the most n-butanol involving blend DB4 (4.0 wt $\%$ oxygen) against analogous values a fully loaded straight diesel produces at a higher speed of $2500 \mathrm{rpm}$. The scientists Sukjit et al. progressed further with totally renewable and environment friendly binary, biodiesel-n-butanol biofuels adding to the intake manifold hydrogen to enhance combustion and drastically reduce $\mathrm{CO}$ and particulate matter (PM) emissions in compression ignition engines [5].

Normal butanol $\left(\mathrm{CH}_{3} \mathrm{CH}_{2} \mathrm{CH}_{2} \mathrm{CH}_{2} \mathrm{OH}\right)$ with molecular weight of $74.12 \mathrm{~g} / \mathrm{mol}$ is an alcoholic-origin colourless liquid of medium volatility and a characteristic banana-like 
odour. It is flammable enough with a flash point of around $35^{\circ} \mathrm{C}$, contains 21.62 wt. $\%$ of fuel-bound oxygen with a boiling point of about $117.40^{\circ} \mathrm{C}$ at $760 \mathrm{~mm} \mathrm{Hg}$. This renewable biofuel added to widely known rapeseed oil methyl ester (RME) reduces density, viscosity, $\mathrm{C} / \mathrm{H}$ atoms ratio and provides plenty of fuel-bound oxygen that along with its good evaporative properties improves both the air and fuel vapours mixing rate and the combustion of biofuel blends. Because biodiesel and n-butanol contain a lower number than traditional diesel fuel the carbon atoms in the molecules, the enhanced combustion takes the advantage to reduce the total amount of both $\mathrm{CO}_{2}$ and $\mathrm{CO}$ emissions below the respective values of neat biodiesel or from a straight diesel could be expected. When being used as an oxygenator source in the above tests, anhydrous, 200 proof, ethanol $\left(\mathrm{CH}_{3} \mathrm{CH}_{2} \mathrm{OH}-99.9\right.$ vol\%) created more concern to the researchers than n-butanol in terms of the blends consistency, auto-ignition delay extension and combustion peculiarities. However, the presence of a lighter n-butanol in biodiesel also reduces the blended cetane number rating, net heating value and thus affects mass of biofuel consumed per unit of energy or effective power developed by an engine. A sensitive interaction between advantageous and disadvantageous operational properties of renewables with a widely differing nature, origin and production technology of biodiesel and n-butanol may lead to ambiguous development trends in the combustion attributes, net heat release rate and engine out emissions [4]. In contrast to ethanol, operational properties of n-butanol are much more similar to those of a straight diesel or biodiesel with the exception of lower density, viscosity and about twice as much lower $\mathrm{CN}$ rating the improvement of which rests on the higher cetane number of biodiesel [8]. Moreover, n-butanol provides operational advantages because its reasonable addition to biodiesel has the potential to drastically reduce the production of $\mathrm{CO}$ and smoke (PM) due to considerably lower $\mathrm{C} / \mathrm{H}$ atoms ratio and high fuel-bound oxygen mass (wt, \%) content. Next, the lower density and viscosity of n-butanol may have positive impact on biofuel injection, atomisation and vaporisation characteristics, the air and fuel vapours mixing rate in the hot in-cylinder compressed air charge, combustion attributes and thus engine out emissions when operating under steady and transient conditions [9].

Wei et al. [6] investigated and compared biodieselethanol $(\mathrm{BE})$ and biodiesel-n-butanol $(\mathrm{BBu})$ blends-made effects on combustion, performance and emissions of a direct-injection diesel engine. Experiments were conducted on a straight diesel, biodiesel and BE5 (5\% ethanol and $95 \%$ biodiesel, v/v), BE10, BE15 and BBu5, BBu10, BBu15 biofuel blends, at five engine loads and constant speed of $1800 \mathrm{rpm}$. The blended fuels lead to higher maximum heat release rate, higher maximum in-cylinder pressure, longer auto-ignition delay, and shorter combustion duration that all in a company evoked adverse effect on combustion noise and stability particularly when running with the BE blends. Moreover, on average of the five engine loads, the $\mathrm{BBu}$ and $\mathrm{BE}$ blends increased $\mathrm{CO}$ emission by $13.7 \%$ and $22.8 \%$ and $\mathrm{HC}$ emission by $5.6 \%$ and $29.2 \%$, respectively; but reduced $\mathrm{NO}_{x}$ emission by $6.5 \%$ and $28.0 \%$, particle mass concentration by $20.7 \%$ and $20.6 \%$ and particle number concentration by $22 \%$ and $21 \%$, respectively. Thus the BE blends revealed themselves as being more effective in reducing particulate and $\mathrm{NO}_{\mathrm{x}}$ emissions, while the $\mathrm{BBu}$ blends suggested less increase in $\mathrm{CO}$ and $\mathrm{HC}$ emissions [6].

Zöldy [7] conducted a wide-range chemical-analytical investigation on properties of butanol, hydrogenated vegetable oil and diesel fuel blends and measured nearly 20 chemical and physical parameters, especially such as flash point, cetane number, viscosity and cold filter plugging point (CFPP) to find out whether or not the three component blends are suitable for compression ignition engines. The researcher estimated that the viscosity decreases within the test range nearly liner and every $1 \%$ of butanol mass content (v/v\%) added to the blend causes slight $1.4 \%$ decreasing effect on viscosity. He also noted that the added butanol decreases the blend's flash point to around $40^{\circ} \mathrm{C}$ that is under the standard DIN EN ISO 2719, revised in 2016, minimum. This decrease is critical from the point of view of transportation fire-safety and logistics security. Because butanol-diesel and/or n-butanol-biodiesel fuel blends are flammable, the security equipment needs to be used as in the gasoline supply chain. Through wide-range experimental tests, the author disclosed that there about a liner relationship exists and the increase by $1 \%$ of butanol in Hydro-treated Vegetable Oil (HVO) content decreases the blended $\mathrm{CN}$ rating with an average of 0.4 points [7].

A lot of the research and development performed on n-butanol using in a diesel engine, however, there is not completely clear what could be the rational renewable biodiesel and n-butanol mixing rate that could be acceptable for diesel-powered machines and power generators. To make a difference, the undertaken research intends to put more light on the changing trends in performance parameters of a diesel engine, biofuels energy conversion efficiency and emissions of the exhaust when running alternately on neat biodiesel (B) derived from rapeseed oil as a 'baseline' fuel and a totally, renewable binary liquid biodiesel-nbutanol blends.

\section{Materials and methods}

Regardless of both biodiesel (B) and n-butanol (Bu) are of the same renewable nature, nevertheless, the production of tested biofuels derives from different resources by using dissimilar technologies, therefore, these biofuels differ as having completely different origins with widely differing chemical and physical properties (Table 1). The totally renewable blends $\mathrm{BBu} 10$ (11.972 wt\% oxygen) and BBu20 (12.336 wt $\%$ oxygen) were prepared by mixing 90 vol.\% $\mathrm{B} / 10 \% \mathrm{Bu}(\mathrm{BBu} 10)$ and 80 vol.\% B/20 vol.\% Bu (BBu20), respectively.

The experimental investigation was carried out in the Engine testing laboratory of Power and Transport Machinery Engineering Institute, Faculty of Agricultural Engineering of Vytautas Magnus University - Agricultural Academy. For stroke, single-cylinder, direct injection, air cooled DEUTZ FL 511 diesel engine was used for these experiments. Load characteristics of an engine were taken when operating at gradually increasing load and constant engine speed of $2000 \mathrm{rpm}$ at which an engine maximum torque develops. The test results of engine operation with various 
biodiesel-n-butanol blends are analysed and compared with the respective parameters measured when running with neat biodiesel derived from rapeseed oil at the respective loads, with particular attention to full $(100 \%)$ engine load, at constant speed of $2000 \mathrm{rpm}$.

Table 1. Chemical and physical properties of tested biofuels

\begin{tabular}{|l|c|c|}
\hline \multicolumn{1}{|c|}{ Parameter } & $\begin{array}{c}\text { Rapeseed oil } \\
\text { biodiesel (B) }\end{array}$ & $\begin{array}{c}\text { n-butanol } \\
(\mathrm{Bu})\end{array}$ \\
\hline Density at $15^{\circ} \mathrm{C}, \mathrm{kg} / \mathrm{m}^{3}$ & 884.7 & 810 \\
\hline Kinematic viscosity, $\mathrm{mm}^{2} / \mathrm{s}$ & 4.8 & 2.63 \\
\hline $\begin{array}{l}\text { Lubricity }(\mathrm{HFRR}), \mathrm{wear} \mathrm{scar} \text { diame- } \\
\text { ter (wsd } 1.4) \text { at } 60^{\circ} \mathrm{C}, \mu \mathrm{m}\end{array}$ & 205 & 591 \\
\hline Flash point, open cup, ${ }^{\circ} \mathrm{C}$ & 168 & 35 \\
\hline Initial / final boiling points, ${ }^{\circ} \mathrm{C}$ & $346 / 366$ & 117.7 \\
\hline Auto-ignition temperature ${ }^{\circ} \mathrm{C}$ & $\sim 342$ & $\sim 343$ \\
\hline Cetane number & 53.4 & 25 \\
\hline Oxygen content, max wt\% & 10.9 & 21.62 \\
\hline Carbon-to-hydrogen ratio $(\mathrm{C} / \mathrm{H})$ & 6.49 & 4.8 \\
\hline Stoichiometric air/fuel ratio, $\mathrm{kg} / \mathrm{kg}$ & 12.62 & 11.12 \\
\hline
\end{tabular}

Torque of an engine was measured with a magnetic powder brake dynamometer PT40M (0-60 N.m) with a definition rate of $\pm 0.5 \mathrm{~N} \cdot \mathrm{m}$ and rotation speed with a mechanical tachometer (150-3000 rpm) with an accuracy of $\pm 0.5 \%$ of the measured value. The air mass consumption was measured with a turbine type gas meter CGT-02 (10$100 \mathrm{~m}^{3} / \mathrm{h}$ ) with an accuracy of $\pm 1 \%$ of the measured value, and fuel mass consumption by using electronic scale SK-1000 with an accuracy of $\pm 0.5 \%$.

Emissions of nitric oxide (NO), nitrogen dioxide $\left(\mathrm{NO}_{2}\right)$, carbon monoxide $(\mathrm{CO})$ in parts per million (ppm) and carbon dioxide $\left(\mathrm{CO}_{2}\right)$ in vol\% were measured with electrochemical cells installed in Testo $350 \mathrm{XL}$ flue gas analyser. Total $\mathrm{NO}_{\mathrm{x}}$ emissions were determined as a sum of both NO and $\mathrm{NO}_{2}$ pollutants with an accuracy of $\pm 5 \mathrm{ppm}$. Exhaust smoke was measured with a Bosch RTT 110 opacity meter with an accuracy of $\pm 0.1 \%$ in a scale range of $0-100 \%$. To improve reliability of the measured data the tests have been repeated no less than three times.

Lubricating properties of the fuels were determined by using the HFRR method. Tests were conducted according to the international standard ISO 12156. The temperature of the fuel was maintained to be of a constant value of about $30^{\circ} \mathrm{C}$ during the lubricity tests.

\section{Analysis of the results and discussions}

\subsection{Lubricity of biodiesel-n-butanol fuel blends}

Columns in Fig. 1 show how the average wear scar of the test ball changed when using the neat biodiesel and biodiesel-n-butanol fuels blends.

The test results demonstrate that the average wear scar with maximum increase in the diameter of $0.395 \mathrm{~mm}$ was obtained when using biofuel BBu30 blend. While the minimum wear scar with the diameter of $0.280 \mathrm{~mm}$ was obtained with neat biodiesel. The Ball On-Cylinder or BOCLE tests showed that biodiesel derived from rapeseed oil has superior lubricity compared to low sulphur diesel fuel [10] and thus the wear-sensitive fuel system designs such as plunger-barrel and the needle-valve-barrel units are able to tolerate n-butanol additions to biodiesel.

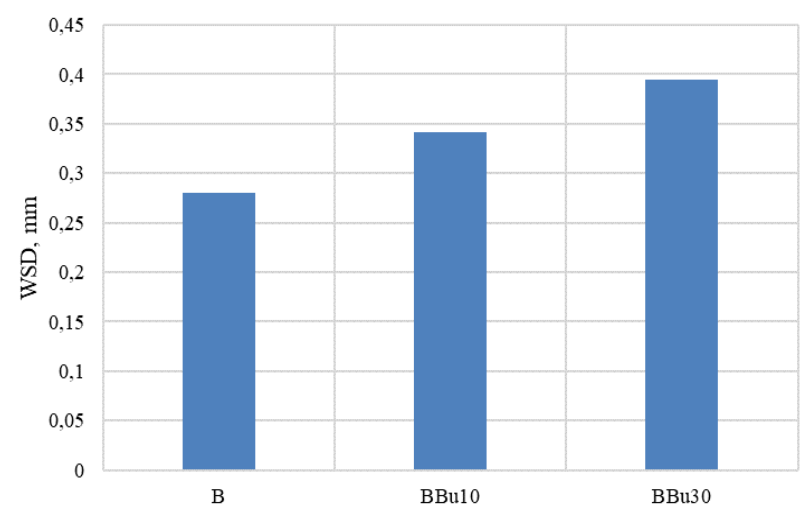

Fig. 1. The dependency of the average wear scar caused by the neat biodiesel and biodiesel-n-butanol fuel BBu10 and BBu30 blends

\subsection{Performance efficiency and emissions from an} engine powered with biodiesel-n-butanol fuel blends

Figure 2 shows the brake specific fuel consumption (bsfc) variations as a function of engine load. The summarised effect of the widely differing chemical and physical properties and net heating values of the biofuels studied along with the changes in the autoignition and combustion peculiarities have influence on the fuel mas burned over an hour $(\mathrm{kg} / \mathrm{h})$ and the fuel mass consumed per unit of effective power $(\mathrm{g} / \mathrm{kWh})$ developed by an engine. As can be seen in graphs, the brake specific fuel consumption (bsfc) for neat biodiesel are lower over the whole load-range tested compared to the engine running on less calorific biodieseln-butanol blends. The noted differences in the bsfc values are mainly observable when running at a light load, low pressure and temperature in the cylinder because the autoignition delay extends due to the presence of more volatile n-butanol with both the cooling effect and the reduced $\mathrm{CN}$ rating that may negatively affect the combustion of the blends. For the above reasons and slightly lower calorific value, the brake specific fuel consumptions for the respective blends $\mathrm{BBu} 10$ and $\mathrm{BBu} 20$ are up to $12.56 \%$ and $16.76 \%$ higher than, $798.7 \mathrm{~g} / \mathrm{kWh}$, neat biodiesel suggests for light-load operation.

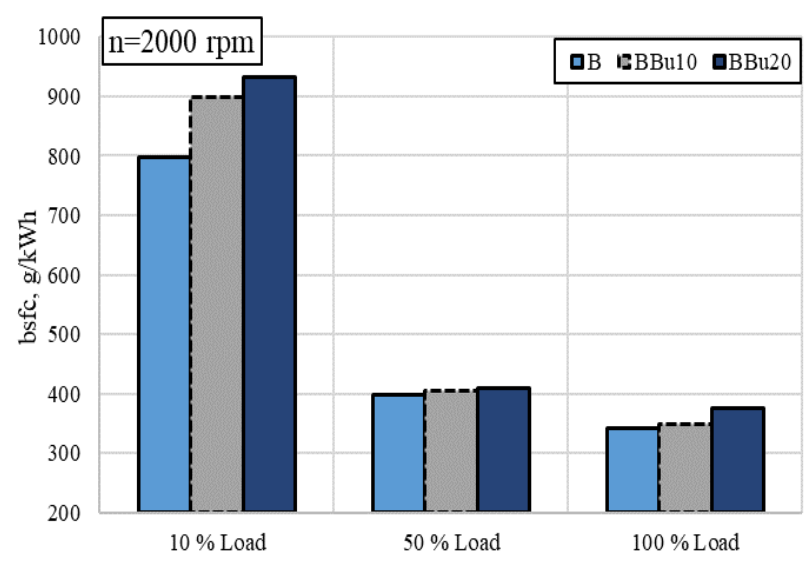

Fig. 2. The brake specific fuel consumption (bsfc) as a function of engine load when running at maximum torque speed of $2000 \mathrm{rpm}$

As soon as the temperature inside the cylinder increases with engine load increased to about medium (50\% of full), the differences in brake specific fuel consumptions are also 
less observable and the bsfc values for the respective blends $\mathrm{BBu} 10$ and $\mathrm{BBu} 20$ sustain at about $1.38-2.80 \%$ higher levels than, $398.4 \mathrm{~g} / \mathrm{kWh}$, the neat biodiesel consumes at considered test conditions.

As could be reasonably expected, the bsfc values remain relatively up to $1.39 \%-9.77 \%$ higher for n-butanol oxygenated biodiesel blends $\mathrm{BBu} 10$ and $\mathrm{BBu} 20$ when running at a full $(100 \%)$ load as well than, $343.1 \mathrm{~g} / \mathrm{kWh}$, neat biodiesel suggests for the same loading conditions at maximum torque speed of $2000 \mathrm{rpm}$. The relatively higher brake specific fuel consumption of binary biofuels $\mathrm{BBu} 10$ and $\mathrm{BBu} 20$ can be mainly attributed to the lower net heating value of plenty oxygenated biodiesel-n-butanol blends.

Figure 3 shows the brake thermal efficiency variations as a function of engine load.

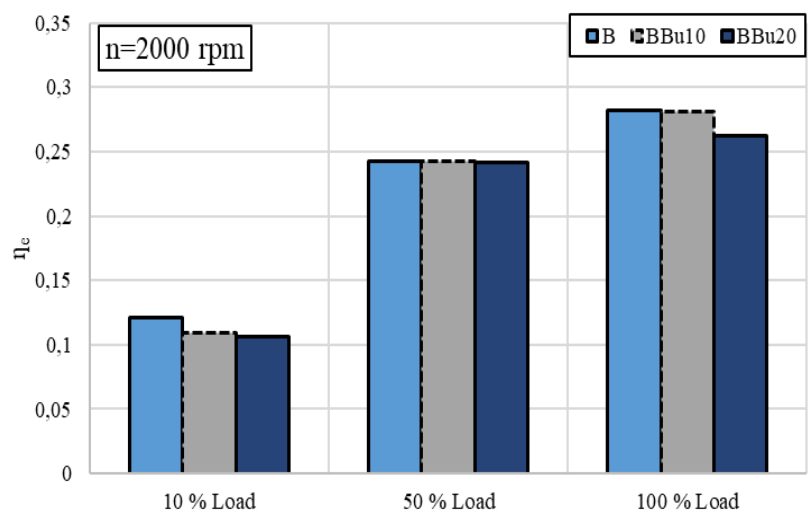

Fig. 3. The brake thermal efficiency as a function of engine load when running at maximum torque speed of $2000 \mathrm{rpm}$

The biggest relative decrease in the brake thermal efficiency of an engine reasonably obtained when running with neat biodiesel and biofuel blends tested under the low loads and thus not as high as would be needed for fuel-efficient combustion the temperature inside the cylinder. As shown in Fig. 3, an engine develops the lowest brake thermal efficiency value of 0.106 ( $14.15 \%$ lower) when running with the most n-butanol oxygenated blend $\mathrm{BBu} 20$ and the maximum one of 0.121 with neat biodiesel at the lowest $(10 \%)$ load. The obtained energy conversion efficiencies of biofuel blends match well with obvious differences in the cetane number, negative changing trends in the combustion noise, engine performance stability and the respective bsfc values (Fig. 2) measured when running with blend BBu20 at the lowest load. The brake thermal efficiency gradually increased with engine load and the temperature inside the cylinder to reach for neat biodiesel the same maximum value of 0.282 , remaining $3.28 \%$ and $7.33 \%$ lower engine efficiencies, 0.273 and 0.263 , for the respective $n$-butanol blends BBu10 and BBu20 when running under full (100\%) load conditions.

The variation of total emissions of nitrogen oxides $\left(\mathrm{NO}_{\mathrm{x}}\right)$ with as a function of engine load and different biofuel blends is presented in Fig. 4. The total $\mathrm{NO}_{\mathrm{x}}$ emissions sustain at a reasonable level when running at the lowest engine load varying within the narrow range from $434 \mathrm{ppm}$ for neat biodiesel to $489 \mathrm{ppm}$ for the biggest mass content of n-butanol containing biofuel $\mathrm{BBu} 20$. The relatively
$12.5 \%$ higher $\mathrm{NO}_{\mathrm{x}}$ emissions emanating from the combustion reaction of the most $n$-butanol involving blend $\mathrm{BBu} 20$ can be reasonably attributed to the fact that the temperature inside the cylinder is too low to keep smooth operation of an engine on plenty n-butanol oxygenated biodiesel blend at the lowest load. Therefore, the increased combustion instability accompanied by the high noise levels and the incylinder pressure oscillations contributed to the production of more $\mathrm{NO}_{\mathrm{x}}$ emissions in this particular low-load conditions. High evaporative cooling effect and low calorific value of n-butanol can be realised in practise bearing in mind that the production of $\mathrm{NO}_{\mathrm{x}}$ relies primary on the temperature inside the cylinder, local oxygen concentration, the residence time limited by the combustion reactions, and relative (overall) air/fuel ratio [11], but less depends on the availability of the local oxygen [12].

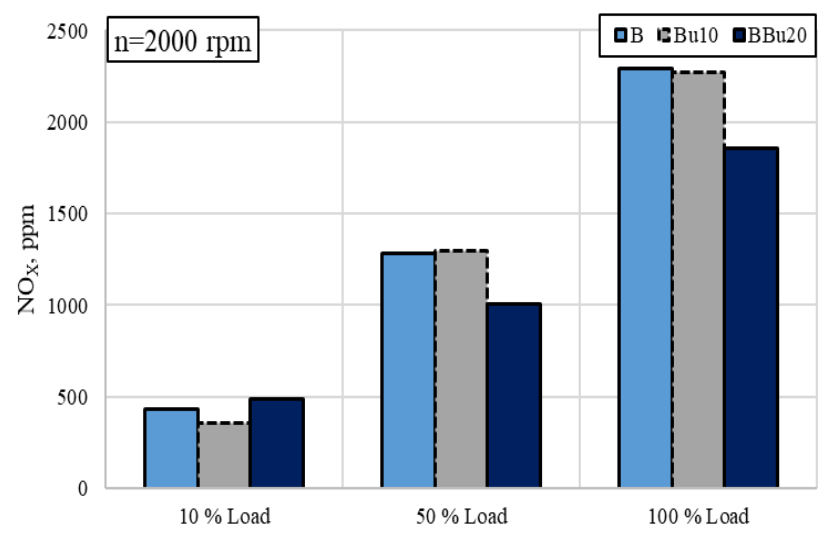

Fig. 4. The total nitrogen oxide $\left(\mathrm{NO}_{\mathrm{x}}\right)$ emissions as a function of engine load when running at maximum torque speed of $2000 \mathrm{rpm}$

The production of $\mathrm{NO}_{\mathrm{x}}$ emissions gradually increases with engine load and thus the temperature inside the cylinder reaching the lowest value, $1280 \mathrm{ppm}$, for neat biodiesel and $1273 \mathrm{ppm}$, for the combustion of biofuel blend BBu10 when running at about medium (50\% of full) load.

As could be expected, the $\mathrm{NO}_{\mathrm{x}}$ emissions increase to the maximum value of $2290 \mathrm{ppm}$ for neat biodiesel sustaining at relatively $0.7 \%$ and $23.5 \%$ lower levels for the respective biodiesel-n-butanol blends $\mathrm{BBu} 10$ and $\mathrm{BBu} 20$ when running under the full $(100 \%)$ load conditions. It is challenging to define the reasons, but in fact, the obtained result provides excellent finding revealing that the higher $n$-butanol mass content (v/v\%) is added to biodiesel blend, the lower actually its contribution to the reduction intensity of maximum $\mathrm{NO}_{\mathrm{x}}$ emissions can be expected. The potential answer to this intriguing question lies perhaps beyond the fact that the $\mathrm{NO}_{\mathrm{x}}$ emissions emerge mainly during the first kinetic combustion phase under the high temperatures above $2000 \mathrm{~K}$ where a key role in the $\mathrm{NO}_{\mathrm{x}}$ production plays the air-borne oxygen. While the biofuel-bound oxygen takes only a second-rate role coming into effect too late in the expansion stroke during the diffusion-controlled combustion phase and thus with a little help to contribute to the $\mathrm{NO}_{\mathrm{x}}$ production. For this reason, the effect of the fuelbound oxygen on the $\mathrm{NO}_{\mathrm{x}}$ emissions changing trends can be ambiguous enough, hardly predictable and dependable on 
the feedstock materials, origin and production technology of the biofuel as well as on the combustion chamber type and the test conditions of an engine, particularly on the relative (overall) air-fuel ratio.

The dependencies of carbon monoxide (CO) emission of engine load is shown in Fig. 5. At the beginning of engine loading, the $\mathrm{CO}$ emissions relatively decrease to be 6.0 and $25.3 \%$ lower mainly for the blends BBu10 and BBu20 case, than neat biodiesel, when running at the lowest load.

As soon as the engine load increases to about medium (50\% of full) value and the temperature inside the cylinder boosts up, both most n-butanol oxygenated blends BBu10 and $\mathrm{BBu} 20$ reveal themselves as having strong potentials to drastically reduce the carbon monoxide (CO) emissions by $10.7 \%$ and $27.3 \%$, respectively. The noted positive CO emissions changing trends with using the most n-butanol oxygenated biodiesel blends $\mathrm{BBu} 10$ and $\mathrm{BBu} 20$ actually remain in value after transition to full $(100 \%)$ load operation as well. The enhanced combustion of the respective blends BBu10 and BBu20 produces the $\mathrm{CO}$ emissions 486 ppm and $374 \mathrm{ppm}$ lower values than, $555 \mathrm{ppm}$, for the neat biodiesel under full (100\%) load operation.

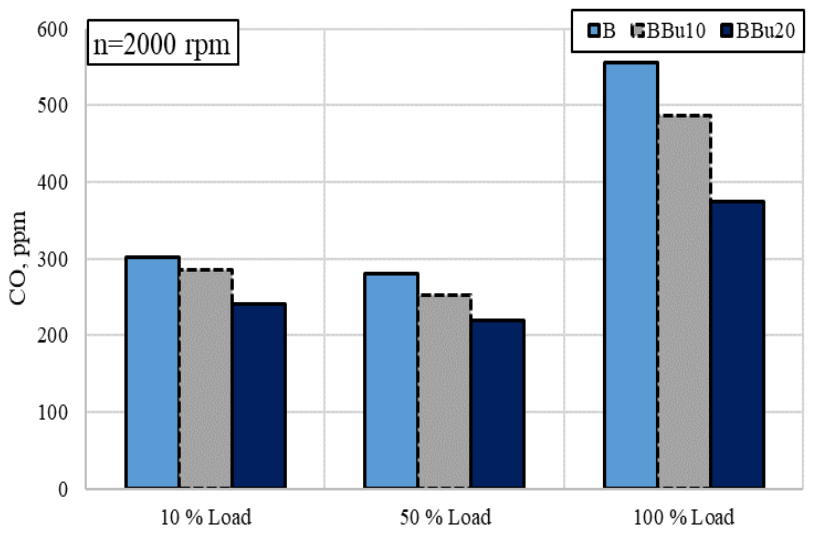

Fig. 5. Dependencies of carbon monoxide (CO) emissions on engine load when running at maximum torque speed of $2000 \mathrm{rpm}$

In contrast to ambiguous the $\mathrm{NO}_{\mathrm{x}}$ emissions behaviour, the positive effect of the lower $\mathrm{C} / \mathrm{H}$ atoms ratio strongly supported by both the absence of polycyclic aromatic hydrocarbons in the composition of biodiesel-n-butanol biofuels and the increased n-butanol-oxygen mass (wt, \%) content, significantly contributes to enhance combustion and thus drastically reduce $\mathrm{CO}, \mathrm{CO}_{2}$ emissions and visible smoke of the exhaust.

Figure 6 shows dependencies of smoke opacity of the exhaust of engine load. Smoke opacity characteristics for the respective n-butanol oxygenated blends $\mathrm{BBu} 10$ and $\mathrm{BBu} 20$ is $52.9 \%$ and $23.5 \%$ higher comparison to the neat biodiesel produces, when running at low load and maximum torque speed of $2000 \mathrm{rpm}$. This phenomenon of smoke is the evidential fact that biofuel vapours do not burn completely at the low load, so they additionally affect transparency of the exhaust if or when the temperature inside the cylinder is not as high as would be needed to support efficient combustion and take under control the cyclic variability of operational parameters. As could be reasonably expected, the lowest smoke opacity produces the combustion of most n-butanol oxygenated blend BBu20 that is $26.7 \%$ lower than, neat biodiesel suggests when running at about medium ( $50 \%$ of full) load.

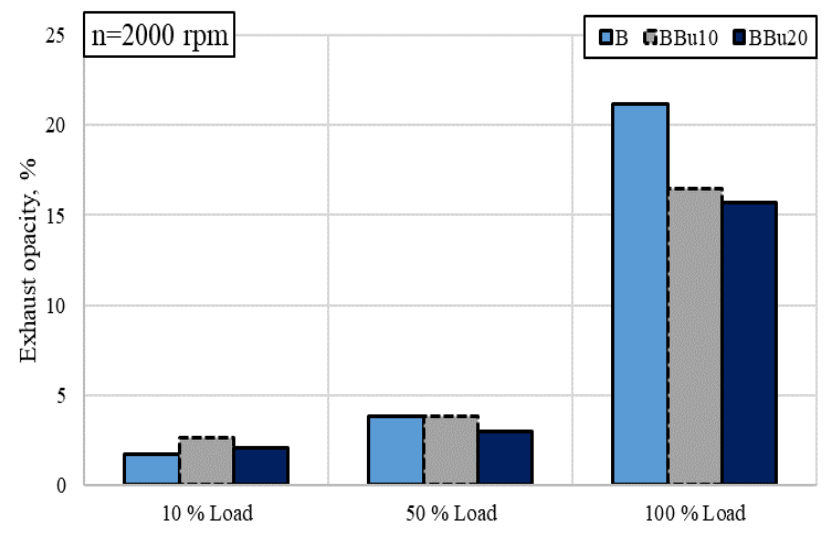

Fig. 6. Dependencies of smoke opacity of the exhaust on engine load when running at maximum torque speed of $2000 \mathrm{rpm}$

When running the engine on biofuel blends $\mathrm{BBu} 10$ and $\mathrm{BBu} 20$ at full $(100 \%)$ load at maximum torque speed of $2000 \mathrm{rpm}$, the smoke opacity decreased by $28.5 \%$ and $35 \%$, respectively, compared to the cases of using neat biodiesel.

\section{Conclusions}

1. Maximum mean diameter of the wear scar was equal to $0.395 \mathrm{~mm}$ when using biodiesel-n-butanol fuel BBu30 blend and the minimum value of the wear scar was measured when running with the neat biodiesel.

2. The brake specific fuel consumption using biodiesel-nbutanol fuel blends increased across at over the whole load range. At full engine load biofuel BBu10 and $\mathrm{BBu} 20$ blends, the break specific fuel consumption increased by $1.39 \%$, and $9.77 \%$, respectively, compared to neat biodiesel. The main reason of having relatively higher the bsfc for oxygenated blends is much lower net heating value of the added n-butanol.

3. Using a biofuel BBu20 blend, the break thermal efficiency was $7.33 \%$ lower, compared to the engine running on neat biodiesel, at full engine load.

4. The highest total $\mathrm{NO}_{\mathrm{x}}$ emissions, $2290 \mathrm{ppm}$, produces the combustion of neat biodiesel, while the positive effect of n-butanol oxygenated biodiesel blends on the $\mathrm{NO}_{\mathrm{x}}$ suppression is not as huge as could be expected. At full engine load and using biofuel $\mathrm{BBu} 20$ blend, the most environmentally and human harmful total emissions of nitrogen oxides decreased $23.5 \%$, respectively.

5. When the engine running at low load, the highest the carbon monoxide emissions were obtained with the engine running on neat biodiesel $(302 \mathrm{ppm})$ and the lowest using the biofuel BBu20 blend (241 ppm). Both most nbutanol oxygenated biodiesel blends $\mathrm{BBu} 10$ and $\mathrm{BBu} 20$ revealed themselves as having strong potentials to drastically reduce the carbon monoxide (CO) emissions for full load.

6. At the full engine load, using biofuel BBu10 and BBu20 blends, the smoke opacity was $28.5 \%$ and $35 \%$ lower, compared to the engine running on neat biodiesel. 
Taking into account the above merits, renewable binary biodiesel-n-butanol blends are suitable for diesel engine powering to replace fossil-origin diesel fuels, reduce the climate change and safe the untouched nature for future generations. Because of the absence of polycyclic aromatic hydrocarbons in renewable biofuel blends, lower maximum
$\mathrm{NO}_{\mathrm{x}}$ and drastically reduced $\mathrm{CO}$ emissions and smoke opacity (PM) could reasonably be expected due to potentially improved homogeneity of combustible mixture and particulate matter (PM) emissions benefits suggested by higher n-butanol-oxygen mass content (21.62 wt\%) and much lower carbon-to-hydrogen ratio (4.8).

\section{Nomenclature}

\begin{tabular}{|c|c|c|c|}
\hline $\mathrm{CN}$ & cetane number & WSD & wear scar diameter \\
\hline B & rapeseed methyl ester & bsfc & brake specific fuel consumption \\
\hline $\mathrm{Bu}$ & n-butanol & bte & brake thermal efficiency \\
\hline $\mathrm{BBu} 10$ & $\begin{array}{l}10 \text { vol\% n-butanol/80 vol\% rapeseed oil methyl } \\
\text { ester; }\end{array}$ & $\begin{array}{l}\mathrm{NO}_{\mathrm{x}} \\
\mathrm{CO}\end{array}$ & $\begin{array}{l}\text { total nitrogen oxides } \\
\text { carbon monoxide }\end{array}$ \\
\hline
\end{tabular}

BBu20 20 vol\% n-butanol/90vol\% rapeseed oil methyl ester

\section{Bibliography}

[1] Directive 2009/28/EC of the European Parliament and of the Council of 23 April 2009 on the promotion of the use of energy from renewable sources and amending and subsequently repealing Directives 2001/77/EC and 2003/30/EC. Available at: eur-lex.europa.eu

[2] GIAKOUMIS, E., RAKOPOULOS, C.D., DIMARATOS, A.M. et al. Exhaust emissions with ethanol or n-butanol diesel fuel blends during transient operation: A review. Renewable and Sustainable Energy Reviews. 2013, 17(1), 170-190. https://doi.org/10.1016/j.rser.2012.09.017

[3] RAKOPOULOS, D.C., RAKOPOULOS, C.D., GIAKOUMIS, E.G. et al. Comparative evaluation of ethanol, nbutanol, and diethyl ether effects as biofuel supplements on combustion characteristics, cyclic variations, and emissions balance in light-duty diesel engine. Journal of Energy Engineering. 2017, 143(2), 04016044-1-04016044-8.

https://doi.org/10.1061/(ASCE)EY.1943-7897.0000399

[4] LABECKAS, G., SLAVINSKAS, S., RUDNICKI, J. et al. The effect of oxygenated diesel-n-butanol fuel blends on combustion, performance, and exhaust emissions of a turbocharged CRDI diesel engine. Polish Maritime Research. 2018, 25, 1(97), 108-120.

https://doi.org/10.2478/pomr-2018-0013.

[5] SUKJIT, E., HERREROS, J.M., DEARN, K.D. et al. Effect of hydrogen on butanol-biodiesel blends in compression ignition engines. International Journal of Hydrogen Energy. 2013, 38(3), 1624-1635.

https://doi.org/10.1016/j.ijhydene.2012.11.061

[6] WEI, L., CHEUNG, C.S., NING, Z. Effects of biodieselethanol and biodiesel-butanol blends on the combustion, performance and emissions of a diesel engine. Energy. 2018, 155, 957-970. https://doi.org/10.1016/j.energy.2018.05.049

Prof. Stasys Slavinskas, DEng. - Institute of Power and Transport Machinery Engineering, Vytautas Magnus University.

e-mail: stasys.slavinskas@vdu.lt

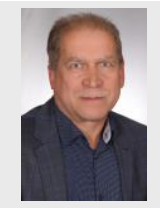

Tomas Mickevičius, DEng. - Institute of Power and Transport Machinery Engineering, Vytautas Magnus University.

e-mail: tomas.mickevicius1@vdu.lt
[7] ZÖLDY, M. Fuel properties of butanol-hydrogenated vegetable oil blends as a diesel extender option for internal combustion engines. Periodica Polytechnica Chemical Engineering. 2020, 64(2), 205-212.

https://doi.org/10.3311/PPch.14153

[8] LABECKAS, G., SLAVINSKAS, S., KANAPKIENĖ, I. Study of the effects of biofuel-oxygen of various origins on a CRDI diesel engine combustion and emissions. Energies. 2019, 12(7), 1241. https://doi.org/10.3390/en12071241

[9] RAKOPOULOS, D.C., RAKOPOULOS, C.D., GIAKOUMIS, E.G. Impact of properties of vegetable oil, bio-diesel, ethanol and n-butanol on the combustion and emissions of turbocharged HDDI diesel engine operating under steady and transient conditions. Fuel. 2015, 156, 1-19,

https://doi.org/10.1016/j.fuel.2015.04.021

[10] GRABOSKI M.S., MCCORMICK R.L. Combustion of fat and vegetable oil derived fuels in diesel engines. Progress in Energy and Combustion Science. 1998, 24(2), 125-164. https://doi.org/10.1016/S0360-1285(97)00034-8

[11] SHAHIR, S.A., MASJUKI, H.H., KALAM, M.A. Performance and emission assessment of diesel-biodiesel- ethanol/bioethanol blend as a fuel in diesel engines: A review. Renewable and Sustainable Energy Reviews. 2015, 48, 6278. https://doi.org/10.1016/j.rser.2015.03.049

[12] PAPAGIANNAKIS, R.G., RAKOPOULOS, D.C., RAKOPOULOS, C.D. Evaluation of the air-oxygen enrichment effects on combustion and emissions of natural gas/diesel dual-fuel engines at various loads and pilot fuel quantities. Energies. 2018, 11(11), 3028.

https://doi.org/10.3390/en11113028

Prof. Gvidonas Labeckas, DEng. - Institute of Power and Transport Machinery Engineering, Vytautas Magnus University.

e-mail: gvidonas.labeckas@vdu.lt 